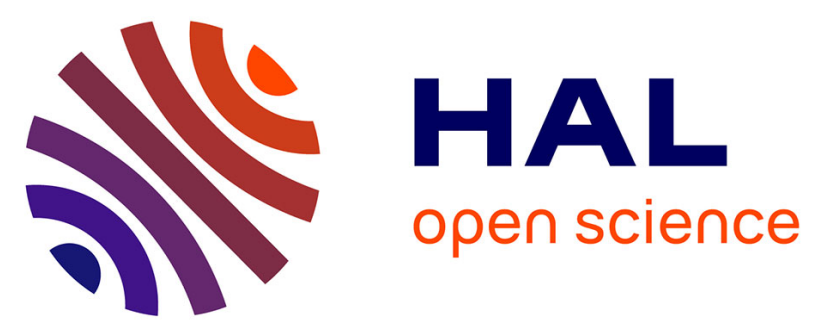

\title{
Formalising Specific-Energy Consumption Under a Production-Management Form Where Rush Orders Are Added in Time Slots
}

Shungo Arai, Hironori Hibino, Takamasa Horikawa, Makoto Yamaguchi

\section{To cite this version:}

Shungo Arai, Hironori Hibino, Takamasa Horikawa, Makoto Yamaguchi. Formalising Specific-Energy Consumption Under a Production-Management Form Where Rush Orders Are Added in Time Slots. IFIP International Conference on Advances in Production Management Systems (APMS), Aug 2018, Seoul, South Korea. pp.50-57, 10.1007/978-3-319-99704-9_7 . hal-02164877

\section{HAL Id: hal-02164877 https://hal.inria.fr/hal-02164877}

Submitted on 25 Jun 2019

HAL is a multi-disciplinary open access archive for the deposit and dissemination of scientific research documents, whether they are published or not. The documents may come from teaching and research institutions in France or abroad, or from public or private research centers.
L'archive ouverte pluridisciplinaire HAL, est destinée au dépôt et à la diffusion de documents scientifiques de niveau recherche, publiés ou non, émanant des établissements d'enseignement et de recherche français ou étrangers, des laboratoires publics ou privés.

\section{(c)(1)}

Distributed under a Creative Commons Attribution| 4.0 International License 


\title{
Formalising Specific-Energy Consumption under a Production-Management Form where Rush Orders Are Added in Time Slots
}

\author{
Shungo Arai ${ }^{1}$, Hironori Hibino ${ }^{1[x]}$, Takamasa Horikawa ${ }^{1}$, \\ and Makoto Yamaguchi ${ }^{2}$ \\ ${ }^{1}$ Tokyo University of Science, 2641 Yamazaki, Noda, Chiba, Japan \\ ${ }^{2}$ Akita University, 1-1, Tegatacho, Akita, Akita, Japan

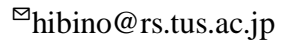

\begin{abstract}
Factory-production activity is conducted based on production plans, which will unavoidably have to be revised due to changes in the production context. These changes should be considered when drafting production plans because of the frequent occurrence of rush orders with short deadlines. Since rush orders interrupt regular orders, we may consider that increased setup times, lower production quantities, and increased specific-energy consumption will accompany their addition.

We have previously supposed a management form that immediately adds rush orders to the production line, and proposed expressions for calculating the specific-energy consumption. Actual companies, looking to restrict increases in setup times, may implement management where rush orders are accumulated and added in time slots. However, in studies on formulae for calculating specific-energy consumption that consider rush orders, we see no consideration of management where the rush orders are added in time slots. Accordingly, this study presents a pre-emptive evaluation method using specific-energy consumption by formalising it for management where rush orders are added in time slots.
\end{abstract}

Keywords: Rush order, specific energy consumption, production management

\section{Introduction}

Efficient energy use is becoming a vital issue in all fields. One concern in industry is the reduction of energy consumed in production activities. Revisions to Japan's Energy Conservation Act stipulate the annual reduction of specific-energy consumption by at least $1 \%$ [1]. In addition, following COP21 (United Nations Climate Change Conference) in December 2015, greenhouse-gas reduction targets have been released, and it is now obligatory to establish measures for attaining these targets [2]. Accordingly, to achieve a more energy-efficient industry, energy-management techniques are needed to understand and analyse in detail how energy is consumed in production processes, and to use energy efficiently [3,4]. Thus, going forward, the industrial world is 
simultaneously considering productivity and energy-consumption amounts, and is seeking both production planning using specific-energy consumption and pre-emptive evaluation methods [5-13].

Factory-production activity is based on production plans. These plans will be unavoidably revised because of the changes in production context that accompany uneven operation times, the arrival of rush orders, etc. When drafting production plans, changes in the production context should be considered. Rush orders with short deadlines should especially be considered because of their frequent occurrence $[14,15]$.

In particular, rush orders interrupt regular orders. When a rush order is added to the production line, setup preparations are needed to set aside the regular order to attend to the rush-order production, and again to return to the regular order. This leads to increased setup times and delayed deliveries.

Trzyna et al. analysed production times for regular orders accompanied by added rush orders [16]. Zhu et al. proposed a mixed-integer linear programming method for minimising the total running time [17]. Other studies have proposed methods for restricting delayed-delivery and setup time increases using production-scheduling methods [18-22]. However, these studies focus on productivity when rush orders are added, and do not assess the energy-consumption amounts.

Meanwhile, the present authors have proposed pre-emptive evaluation methods that consider the energy-consumption amounts in addition to productivity [10-13]. In these pre-emptive evaluation studies, expressions for calculating the specific-energy consumption have been proposed. In particular, in one of our studies on calculating specific-energy consumption while considering rush orders, we supposed and formalised a management form that immediately adds rush orders to the production line [13].

We see that actual companies, looking to restrict increases in setup times, may implement management forms where rush orders are added in certain time slots; namely, rather than adding rush orders to the production line immediately, this management form will enter rush-order production after a certain period of time, once the lot size is larger [23]. However, studies on formulae for calculating specific-energy consumption that consider rush orders do not consider management where rush orders are added in time slots.

Accordingly, this study presents a pre-emptive evaluation method that formalises specific-energy consumption for management where rush orders are added in time slots. Specifically, we suppose a management form where rush orders are not added immediately to the production line; instead, time slots are set aside for building larger lot sizes. Under this supposition, we derive the total time for each production facility state, derive the total energy-consumption amount, and propose a formula for calculating the specific-energy consumption. 


\section{Formalising the Specific-Energy Consumption}

\section{1 Specific-energy consumption}

In industry, 'specific-energy consumption' has become an indicator for assessing the production quantity versus the energy consumed during production [24]. In this study, we define specific-energy consumption $S E C$ as follows.

$$
S E C=\frac{E}{P},
$$

where:

$S E C$ is the specific energy consumption [kWs/product],

$P$ is the total production quantity in the production line, and

$E$ is the total energy consumption $[\mathrm{kWs}]$.

\section{2 Preconditions}

This study presumes the following conditions.

- The state of a production facility (herein, 'facility') will either be running, setup, or idle.

The facilities are linked in series.

- Rush orders appear according to a 'generation interval' GIRO [seconds/unit]; the generation interval is fixed, irrespective of time.

- The total operation time $T$ [seconds] is sufficient in duration.

- There are buffers prior to each facility, and the buffer capacity is unlimited.

\subsection{Production form in this study}

In this study, we suppose a management form where rush orders are added in time slots [23]. Specifically, this is where rush orders are added into rush-order-addition time slots, and their production interrupts the regular orders. Meanwhile, time slots not allocated to rush-order additions ('no-addition slots') are slots during which rush orders will be buffered (i.e. and not acted upon). Any rush orders that arrive during the no-addition slots will be collectively entered into production at the start of the next rush-order-addition time slot.

\subsection{In-process inventory coefficient $q^{k}$}

We define the in-process inventory coefficient as the value of facility $k$ 's production quantity $P^{k}$ over the total production quantity $P$. Here, we can express the production quantity for each facility, using the total production quantity.

$$
q^{k}=\frac{P^{k}}{P}
$$


where:

Superscript $k$ is the ordinal number of the $k$-th facility in the production line, $q^{k}$ is the coefficient of facility $k$ 's in-process inventory, and $P^{k}$ is the production quantity of facility $k$.

\subsection{Total run-time $T_{r}^{k}$ for facility $k$}

Facility $k$ 's production quantity $P^{k}$ is the product of the facility's throughput $p_{r}^{k}$ and running time $T_{r}^{k}$; it can therefore be expressed as follows.

$$
T_{r}^{k}=\frac{p^{k}}{p_{r}^{k}}=\frac{q^{k} P}{p_{r}^{k}},
$$

where:

Subscript $r$ indicates that the facility is in its running state,

$T_{r}^{k}$ is the total running-state time of facility $k$ [seconds], and

$p_{r}^{k}$ is the throughput in facility $k$ [products/second].

\subsection{Total setup time $T_{s}^{k}$ for facility $k$}

The setup time $T_{s}^{k}$ is the product of facility $k$ 's per-work setup time $\operatorname{Set} U p^{k}$ and its production quantity $P^{k}$; it can therefore be expressed as follows. SetUp ${ }^{k}$ is detailed later in Section 2.8 .

$$
T_{s}^{k}=P^{k} \times \operatorname{Set} U p^{k}=q^{k} P \times \operatorname{Set} U p^{k},
$$

where:

Subscript $s$ indicates that the facility is in its setup state,

$T_{s}^{k}$ is the total setup-state time of facility $k$ [seconds], and Set $U p^{k}$ is the per-work setup time of facility $k$ [seconds/product].

\subsection{Total idle time $T_{i}^{k}$ for facility $k$}

The idle time is the total operating time $T$ minus the running time and setup time; accordingly, it may be expressed as follows.

$$
T_{i}^{k}=\mathrm{T}-T_{r}^{k}-T_{s}^{k},
$$

where:

Subscript $i$ indicates that the facility is in its idle state, and $T_{i}^{k}$ is the total idle-state time of facility $k$ [seconds].

\section{8 Specific-energy consumption $S E C^{k}$ for facility $k$}

If we take the electricity consumption for each of the states of facility $k$ to be $e_{r}^{k}, e_{s}^{k}$, and $e_{i}^{k}$, respectively, the energy consumption $E^{k}$ in facility $k$ is as follows. 


$$
E^{k}=e_{r}^{k} T_{r}^{k}+e_{s}^{k} T_{s}^{k}+e_{i}^{k} T_{i}^{k}
$$

where:

$e_{r}^{k}$ is the electricity consumption per unit time in the running state of facility $k$, $e_{s}^{k}$ is the electricity consumption per unit time in the setup state of facility $k$, and $e_{i}^{k}$ is the electricity consumption per unit time in the idle state of facility $k$.

The specific-energy consumption for facility $k, S E C^{k}$, is as follows.

$$
\begin{aligned}
S E C^{k} & =E^{k} / P \\
& =\left(\left(e_{r}^{k} T_{r}^{k}+e_{s}^{k} T_{s}^{k}+e_{i}^{k} T_{i}^{k}\right)\right) / P \\
& =q^{k}\left(\frac{e_{r}^{k}}{p_{r}^{k}}+e_{s}^{k} \operatorname{Set} U p^{k}\right) \\
& +e_{i}^{k}\left(\frac{1}{p}-q^{k}\left(\frac{1}{p_{r}^{k}}+\operatorname{Set} U p^{k}\right)\right),
\end{aligned}
$$

where:

$p$ is the throughput for the entire production line [products/second].

Since throughput $p$ is the minimum throughput value if facility $k$ were to operate independently, i.e. for $p_{0}^{k}$, it may be expressed as follows.

$$
p=\min \left\{p_{0}^{1}, p_{0}^{2},,,, p_{0}^{k},,,, p_{0}^{n}\right\}
$$

Here, $p_{0}^{k}$, the throughput from facility $k$, if it were to operate independently, is the reciprocal value of the sum of the per-work setup time and the cycle time in facility $k$, as shown in Formula (9).

$$
p_{0}^{k}=\left(\frac{1}{p_{r}^{k}}+\operatorname{Set} U p^{k}\right)^{-1}
$$

The total setup time for facility $k, T_{s}^{k}$, is the sum total of the setup time for the sections producing only rush orders, the setup time for sections producing both rush orders and regular orders, and the setup time for sections producing only regular orders. Accordingly, the per-work setup time $\operatorname{Set} U p^{k}$ can be expressed as below in Formula (10). 


$$
\begin{aligned}
\operatorname{SetU} & p^{k}=\frac{T_{S}^{k}}{q^{k} P} \\
& =\frac{\lambda^{k}}{L S}+\frac{R t \times\left(\mu^{k}+v^{k}\right)}{q^{k} p \times t_{\text {no-addition }}} \\
& +\frac{1-R t}{q^{k} p \times G I R O} \times\left(\mu^{k}+v^{k}-\frac{L S_{R O}}{L S} \lambda^{k}\right) \\
& -\frac{R t}{q^{k} p \times G I R O} \times\left(\frac{\mu^{k}+v^{k}}{t_{n o-a d d i t i o n}}+\frac{L S_{R O} \times A^{k}}{p_{r}^{k} \times G I R O}\right) \times\left(\mu^{k}+v^{k}-\frac{L S_{R O}}{L S} \lambda^{k}\right) \\
& -\frac{R t \times L S_{R O}}{q^{k} p \times G I R O} \times A^{k} \times \frac{\lambda^{k}}{L S}
\end{aligned}
$$

where:

$\lambda^{k}$ is the setup time between regular orders [seconds],

$\mu^{k}$ is the setup time from a regular order to a rush order [seconds],

$v^{k}$ is the setup time from a rush order to a regular order [seconds],

$L S$ is the lot size of the regular order,

$L S_{R O}$ is the lot size of the rush order,

$d$ is the number of times that rush orders are collated (i.e. number of time slots), and $t_{n o-a d d i t i o n}$ is the length of time during which rush orders are not added [seconds/day].

In this study, we assume $d$ is same value as the number of days in the schedule.

$$
R_{t}=\frac{d t_{n o-a d d i t i o n}}{T}
$$

Here, when there are only rush-order-addition slots, i.e. when $d t_{n o-a d d i t i o n}=0$, then $R_{t}=0$. This indicates that the company's management form is to add rush orders to the production line immediately.

We also define common term $A^{k}$ as follows.

$$
A^{k}=1+\frac{\mu^{k}}{t_{\text {no-addition }}}+\frac{L S_{R O}}{p_{r}^{k} \times G I R O}
$$

Above, we proposed Formula (7) for calculating the specific-energy consumption, as well as Formulae (10), (11), and (12) for calculating Formula (7)'s setup time per-

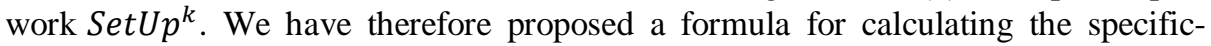
energy consumption under a management form where rush orders are added in time slots.

\section{Conclusion}

In this study, we presented a pre-emptive evaluation method for simultaneously assessing both the energy-consumption amount and productivity of a production facility by proposing a formula for specific-energy consumption that considers rush orders. In particular, we proposed a formula for calculating the specific-energy consumption that supposes a management form where rush orders are added in time slots. 
In the future, we will verify the validity of our proposed formula by undertaking case studies.

\section{References}

1. International Energy Agency (IEA)-Japan, https://www.iea.org/policiesandmeasures/pams/japan/name-30692-en.php, last accessed 2018/4/5.

2. United Nations Framework Convention on Climate Change, Adoption of the Paris agreement, http://unfccc.int/resource/docs/2015/cop21/eng/109r01.pdf, last accessed 2018/3/30.

3. Ministry of Economy, Trade and Industry. Long-term Energy Supply and Demand Outlook, http://www.meti.go.jp/english/press/2015/pdf/0716_01a.pdf, last accessed 2018/5/18.

4. Ministry of Economy, Trade and Industry, Energy innovation strategy, http://www.meti.go.jp/press/2016/04/20160419002/20160419002-2.pdf, last accessed 2018/5/18 (in Japanese).

5. He, Y., Liu, B., Zhang, H., Gao, H., Liu, X.: A modeling method of task-oriented energy consumption for machining manufacturing system. Journal of Cleaner Production 23(1), 167-174 (2012).

6. Wilson, J., Arokiam, A., Belaidi, H., Ladbrook, J.: A simple energy usage toolkit from manufacturing simulation data. Journal of Cleaner Production 122, 266-276 (2016).

7. Ainha, R., Chaturvedi, N.: A graphical dual objective approach for minimizing energy consumption and carbon emission in production planning. Journal of Cleaner Production 171, 312-321 (2018).

8. Heilala, J., Vatanen, S., Tonteri, H., Jari, M., Salla, J., Björn, J., Johan, S.: Simulation-based sustainable manufacturing system design. In: Mason, S., Hill, R., Mönch, L., Rose, D., (eds.) 2008 Winter Simulation Conference, pp. 1922-1930. Miami, FL, USA (2008).

9. Sakuma, T., Hibino, H., Yamaguchi, M.: Manufacturing system simulation for evaluation of productivity and energy consumption. Journal of Advanced Mechanical Design, Systems, and Manufacturing 8(2), 178-189 (2013).

10. Yamaguchi, M., Kobayashi, T., Hibino, H.: Manufacturing system simulation to evaluate energy productivity (Formulation of relationship between productivity and energy consumption). Transactions of the JSME 82(835), 15-00495 (2016) (in Japanese).

11. Kobayashi, T., Yamaguchi, M., Hibino, H.: Manufacturing system simulation to evaluate energy productivity (A study on lot size dependence for energy consumption per unit of production throughput considering breakdown states). Transactions of the JSME 82(835), 15-00502 (2016) (in Japanese).

12. Hibino, H., Yamamoto, M., Yamaguchi, M., Kobayashi, T.: A Study on Lot-Size Dependence of Energy Consumption per Unit of Production Throughput Considering Buffer Capacity. International Journal of Automation Technology 11(1), 46-55 (2017).

13. Kobayashi, T., Yamaguchi, M., Hibino, H.: Lot Size Dependence for Energy Consumption per Unit of Production Throughput Considering Rush Orders in Manufacturing Line. IFAC-StudysOnLine 50(1), 5000-5005 (2017). doi: 10.1016/j.ifacol.2017.08.904.

14. Tanimizu, Y., Komatsu, Y., Ozawa, C., Iwamura, K., Sugimura, N.: Extension of Reactive Scheduling Method Using Co-Evolutionary Genetic Algorithms (Application to Open Shop Scheduling Problems and Experimental Evaluation). Transactions of the JSME, Series C 79(802), 2207-2220 (2013) (in Japanese). 
15. Hendry, L., Land, M., Stevenson, M.: Investigating implementation issues for workload control (WLC): A comparative case study analysis. International Journal of Production Economics 112(1), 452-469 (2008).

16. Trzyna, D., Kuyumcu, A., Lödding, H.: Throughput Time Characteristic of Rush Orders and their impact on Standard Order. Procedia CIRP 3, 311-316 (2012).

17. Zhu, J., Gu, X., Jiao, B.: Efficient Short-term scheduling of multiproduct batch plants under demand uncertainty. Progress in Natural Science 18(4), 487-493 (2008).

18. Sakaguchi, T., Tanimizu, Y., Sugimura, N.: Genetic Algorithm Based Reactive Scheduling $\left(2^{\text {nd }}\right.$ Report, Modification of Production Schedule for Additional Jobs). Transactions of JSME, Series C 71(711), 3299-3305 (2005) (in Japanese).

19. Tanimizu, Y., Komatsu, Y., Ozawa, C., Iwamura, K., Sugimura, N.: Co-evolutionary Genetic Algorithms for Reactive Scheduling. Journal of Advanced Mechanical Design, Systems, and Manufacturing 4(3), 569-577 (2010).

20. Kaihara, T., Yao, Y.: A new approach on CPS-based scheduling and WIP control in process industries. In: Proceedings of the 2012 Winter Simulation Conference, Berlin, Germany (2012).

21. Yao, Y., Kaihara, T., Sashio, K.: A study on Action Type scheduling method for Machining Job Shop -Auction Method for managing Priority Jobs. In: 49th Japan Automatic Joint Control Conference, J-STAGE (2006) (in Japanese). doi: https://doi.org/10.11511/jacc.49.0.525.0.

22. Yao, Y., Kaihara, T., Fujii, N., Hori, E.: A study on Method of Automated scheduling for Dynamically Changing Manufacturing Environment. Transactions of JSME, Series C 77(784), 4718-4729 (2011) (in Japanese).

23. Daitokkyuu! printkiban.com, Considering delivery times, http://daitokkyukiban.com/time/, last accessed 2018/4/2 (in Japanese).

24. Ministry of Economy, Trade and Industry, Strategic Energy Plan, http://www.enecho.meti.go.jp/en/category/others/basic_plan/pdf/4th_strategic_energy_plan. pdf, last accessed 2018/5/19. 